\title{
Agroecologia e sistemas complexos: uma reflexão sobre o estado de Rondônia
}

\author{
Agroecology and complex systems: a reflection on the state of Rondônia
}

Eliane Alves da Silva ${ }^{1 *}$, Eugenio Avila Pedrozo ${ }^{2}$, Mariluce Paes de Souza ${ }^{3}$, Tania Nunes da Silva ${ }^{1}$

\section{RESUMO}

A agroecologia traz inovações técnicas e sociais que levam a repensar a contribuição do movimento orgânico para resolver os desafios como a segurança alimentar, as alterações climáticas e questões ambientais. Portanto o objetivo deste artigo é analisar o desenvolvimento da agroecologia no estado de Rondônia mediante de uma lente teórica que enfatize as interfaces cognitivas entre as propostas atuais, o ambiente, a economia e a sociedade. Por meio de uma pesquisa qualitativa, exploratória e descritiva e um estudo multicasos que comtemplou o Projeto RECA, o Assentamento Padre Ezequiel e a Secretaria de Agricultura (SEAGRI) buscou-se levantar dados para que o paradigma moriniano da complexidade fosse o método para compreender os processos, as articulações, as implicações, as interdependências entre os sistemas sociais e naturais. As informações provenientes dos dados primários e secundários foram analisadas por análise de conteúdo. Foi observado que se pode coordenar melhor as iniciativas futuras para constituir políticas públicas, projetos público-privados ou parcerias com o terceiro em benefício dos sistemas agroecológicos.

Palavras-chave: Agroecologia; Complexidade; Políticas Públicas.

\begin{abstract}
Agroecology brings technical and social innovations that lead to rethinking the contribution of the organic movement to solving challenges such as food security, climate change and environmental issues. Therefore, the aim of this article is to analyze the development of agroecology in the state of Rondônia through a theoretical lens that emphasizes the cognitive interfaces between current proposals, the environment, the economy and society. Through qualitative, exploratory and descriptive research and a multi-case study that covered the RECA Project, the Padre Ezequiel Settlement and the Secretariat of Agriculture (SEAGRI) sought to collect data to the Morinian paradigm of complexity be the method to understand the processes, articulations, implications, interdependencies between social and natural systems. Information from primary and secondary data was analyzed using content analysis. It was observed that future initiatives can be better coordinated to form public policies, public-private projects or partnerships with the third party for the benefit of agroecological systems.
\end{abstract}

Keywords: Agroecology; Complexity; Public Policies; Family.

\footnotetext{
${ }^{1}$ PPGA/EA/UFRGS

*E-mail: eliane.alves@ufrgs.br

${ }^{2}$ Professor Titular PPGA/EA/UFRGS; PPGA/UNIR/RO; PRODEMA/UFPB/PB

${ }^{3}$ Professora Titular PPGA/UNIR/RO
} 


\section{INTRODUÇÃO}

As diferentes abordagens econômicas estabelecem diferentes formas de interpretar, analisar e propor alternativas à crise socioambiental, até porque, enquanto a visão neoclássica e a Economia do Meio Ambiente supõem que a Ecologia estaria a serviço da Economia, na perspectiva da Economia Ecológica é a Economia que está subordinada à Ecologia e não o inverso. Enquanto a economia convencional sugere que todos os problemas podem ser resolvidos no âmbito das relações econômicas, a Agroecologia propõe uma mudança de enfoque, da qual se possa estudar e entender como as atividades econômicas afetam o ambiente, assim como a maneira como elas determinam o uso dos recursos naturais, alterando as relações ecológicas pré-existentes.

Os investimentos no setor produtivo de Rondônia são focados para a tecnologia, apoio financeiro e segurança jurídica das cadeias produtivas de café, leite, cacau, piscicultura, algodão, soja, pecuária de corte e agroindústria familiar. Somente em 2011 com a lei estadual $n^{\circ} 2.588$ iniciou-se alguns esforços em relação à Agroecologia, com o objetivo de promover, integrar e ações para induzir a transição agroecológica e a produção orgânica de base agroecológica.

Em meio a essas iniciativas, surgem como potenciais atores institucionais, no âmbito federal, o Ministério da Agricultura Pecuária e Abastecimento (MAPA), Empresa Brasileira de Pesquisa Agropecuária (EMBRAPA), Instituto Nacional de Colonização e Reforma Agrária (INCRA), Banco da Amazônia (BASA), Agência Nacional de Vigilância Sanitária (ANVISA); no âmbito estadual Secretaria Estadual de Agricultura (SEAGRI), Entidade Autárquica de Assistência Técnica e Extensão Rural do Estado de Rondônia (EMATER-RO); e no âmbito municipal a Secretaria Municipal de Agricultura (SEMAGRIC).

Os outros atores são as organizações sociais caracterizada pela Rede de Agroecologia Terra Sem Males, a qual é formada pela Comissão Pastoral da Terra (CPT), Cooperativa de Produtores Rurais Organizados para Ajuda Mútua (COOCARAM), Projeto. Padre. Ezequiel, Movimento dos Sem Terra (MST), Movimento dos Pequenos Agricultores (MPA), Movimento dos Atingidos por Barragens (MAB), Associação das Escolas Família Agrícola de Rondônia (AEFARO) e Escolas Família Agrícola (EFA's). Além dos atores dessa Rede se reconhece os Povos Tradicionais, como Quilombolas, Seringueiros, Indígenas e Ribeirinhos; o Projeto 
RECA; e Federação dos Trabalhadores Rurais Agricultores e Agricultoras Familiares do Estado (FETAGRO).

A adoção da Agroecologia traz inovações técnicas e sociais que levam a repensar a contribuição do movimento orgânico para resolver os desafios como a segurança alimentar, as alterações climáticas e questões ambientais. Acredita-se que no Estado de Rondônia, quanto mais pessoas passarem a adotar práticas orgânicas haverá contribuições na renovação com foco na sustentabilidade. Mas como apresentar esses impactos subjetivos nessa cadeia de produção que envolve agricultores familiares? Em resposta a esse questionamento o objetivo deste artigo é analisar o desenvolvimento da Agroecologia no estado de Rondônia por meio de uma lente teórica que enfatize as interfaces cognitivas entre as propostas atuais, o ambiente, a economia e a sociedade.

A Agroecologia enquanto saber socioambiental requer uma abordagem que seja capaz de colocar em comunicação crescente e duradoura as ciências da sociedade e da natureza com os demais saberes culturalmente produzidos. A criação deste corpo integrado de conhecimentos sobre os processos naturais e sociais implica, portanto, a integração interdisciplinar e o diálogo de saberes para explicar o comportamento de sistemas socioambientais complexos. Por sua vez, o paradigma da complexidade (MORIN, 2005) apresenta-se como método para compreender as articulações, as implicações, as interdependências das realidades socioambientais. Fundamenta-se na ideia de sistema inserido na unidade no múltiplo, sintetizada no conceito de auto-ecoorganização.

Para atingir o objetivo, se estabeleceu um estudo multicasos que abrangeu o Projeto RECA, o Assentamento Padre Ezequiel e a SEAGRI. Foram realizadas pesquisas por dados primários e secundários, observação não participante e 5 entrevistas em profundidade realizadas com 1 representantes da SEAGRI, 1 representante do Assentamento Padre Ezequiel, 3 representantes da Associação dos Pequenos Agrossilvicultores do Projeto RECA e Cooperativa Agropecuária e Florestal do Projeto RECA.

\section{AGROECOLOGIA E SISTEMAS COMPLEXOS}

Um sistema de entendimento e explicação da realidade, segundo Floriani (2009) ocorre e decorre de trocas e conflitos de significação de objetos materiais, crenças, valores, interesses consubstanciados em sistemas sociais que desenvolvem práticas 
materiais de produção, apropriação e reprodução das condições de existência de uma determinada organização social. Nesse sentido, MORIN (2011) aponta para a necessidade histórica de encontrar um método capaz de detectar, sem ocultar, as ligações, as articulações, as solidariedades, as implicações, as interferências, as interdependências e as complexidades" (MORIN, 2011).

No contexto presente figuram a desordem e a incerteza como protagonistas de um cenário vivo, complexo e caótico. Conforme a teoria da complexidade, a ordem e a desordem, isoladas, são duas calamidades. Por esse motivo Morin (2011) reorienta as formas de manipulação produtiva da natureza. Vale ressaltar que esse novo sistema de regras de pensamento e ações sociais está sustentado por valores como qualidade de vida, identidades culturais e sentidos da existência que não objetivam a ciência, sendo que a estratégia cognitiva complexa se realiza no diálogo entre os saberes acadêmicos e os saberes derivados de práticas socioambientais culturalmente arraigados. Abre-se, dessa forma, um diálogo entre ciência e saber, tradição e modernidade (LEFF, 2011).

Seguindo esse pressuposto, Azevedo (2007) propõe que o conceito de ideótipo agrícola está vinculado ao modelo idealizado de sistema agrícola, construído a partir da cosmologia, o sistema de crenças, a rede simbólica, de cada grupo social. Em complemento, Victor Toledo (2001) envolve as percepções de natureza que uma coletividade constrói com sua rede de crenças e conhecimentos, isto é, o sistema de crenças ou cosmovisões, traduzido em um sistema cognitivo, que legitima o conjunto de práticas sociais. Estas categorias formam, segundo o mesmo autor, o complexo "crenças-conhecimentos-práticas" das coletividades, capaz de evidenciar os processos de apropriação humana da natureza.

Com relação ao conjunto de práticas sociais, Brandenburg (2016) destaca a existência de um costume agrícola ecossocial, definindo-o como a prática social da produção familiar de base ecológica que está alicerçada em sistemas de conhecimentos constituídos por uma nova racionalidade, um novo sistema cognitivo. Este hábito está integrado à subjetividade, ou seja, ao pleno envolvimento do sujeito. Esse reencontro das dimensões materiais e materiais da natureza transformada pelo pensamento em toda sua realidade, consciente e inconsciente, individual e coletivamente, encontra ambiente fértil nas explicações sobre a relação território-territorialidade, posto que "a natureza é realidade material e ao mesmo tempo ideal; é natureza apropriada, humanizada, transformada em sociedade, história inscrita na natureza” (GODELIER, 1984). 
$\mathrm{O}$ enfoque territorial tem um significado muito relevante nas diferentes perspectivas analíticas que trabalham o tema do desenvolvimento rural. O território, nessa nova perspectiva, passou a figurar como importante unidade de análise dos problemas das ações políticas sobre o espaço, levando-se em conta o esgotamento teórico e prático das ações de planejamento funcional do espaço como referência para se pensar as ações e políticas públicas voltadas ao desenvolvimento rural. Nesse sentido, esse rural contemporâneo é um rural que começa a ser pensado como territórios do futuro, como resposta possível à crise do emprego e da qualidade de vida gerada pela civilização urbano-industrial. Tais territórios apresentam-se opostos à posição teórica da homogeneização do rural, surgindo como posição da reconstrução e ressignificação do mesmo (CAPORAL; COSTABEBER; PAULUS, 2009).

O rural ressignificado exige a construção de novas identidades (territorialidades), a partir da valorização de outras dimensões do território que não somente a econômica. Assim, é fundamental destacar valores subjugados pela racionalidade econômico-instrumental implícita nos planos de desenvolvimento do espaço rural: os saberes produzidos localmente. Trata-se de interpretar a configuração de territórios da agricultura familiar ecológica que se expressam como lugares alternativos aos grandes espaços "vazios e estéreis" dos commodities valorizados sazonalmente pelo mercado e pensados de acordo com o projeto modernizador e homogeneizador para o espaço rural. (CAPORAL et al., 2009)

Para reforçar essa interpretação, o pensamento complexo proposto por Morin (2005) utiliza sete princípios. O primeiro é o princípio sistêmico, que une o conhecimento das partes com o conhecimento do todo. Sua ideia central é a de que o todo é mais do que a soma das partes e a organização do todo produz propriedades em relação às partes isoladamente. Isso é observado nas emergências. O segundo princípio, é o hologramático, o qual coloca em evidência esse aparente paradoxo dos sistemas complexos nos quais a parte não somente está no todo, como todo está inscrito em toda parte. O terceiro princípio é o do ciclo retroativo, que permite o conhecimento dos processos autorreguladores. Nesse mecanismo de regulação, conhecido como homeostática, percebe-se o permite a autonomia de um sistema.

O quarto princípio caracteriza-se pela noção de regulação, que ocorre por meio de autoprodução e auto-organização. A partir do qual os produtos e as consequências são eles próprios produtores e originadores daquilo que produzem. O quinto princípio 
da auto-eco-organização, também conhecido como autonomia/dependência, descreve os seres vivos como seres auto-organizados, que se autoproduzem sem cessar e por isto gastam a energia para salvaguardar sua autonomia. O sexto princípio conhecido como dialógico, mostra uma dialógica entre a ordem, a desordem e a organização, por meio de inúmeras inter-retroações. Segundo Morin (2005), a dialógica permite aceitar racionalmente a associação de noções contraditórias para conceber um mesmo fenômeno complexo. E por fim, o sétimo princípio da reintrodução do conhecido em todo o conhecimento (MORIN, 2005).

Entretanto, em seu livro "O método III: o conhecimento do conhecimento", Morin (2011), propõe que os princípios do pensamento complexo podem ser agrupados em três princípios inter-relacionados: o Princípio Dialógico; o Princípio Autogerativo e; o Princípio Hologramático. Caporal et al. (2009) preconizam utilizar esses três conceitos para se discutir Agroecologia. A análise da Agroecologia em função dos três princípios sintéticos da complexidade, dialógico, autogerativo e hologramático, não busca uma clara separação das suas noções, experiências e concepções. Contrariamente, o que se presencia são conexões, sobreposições e recorrências, demonstrando que o método para o pensamento complexo deve indicar um certo nível de complexidade organizacional (MORIN, 2011).

O agroecossistema envolve vários níveis de inter-relação entre os elementos geossistêmicos organizados hierarquicamente, presumindo os enfoques multiescalar e multidimensional para evidenciar tais conexões, ou seja, a integração dos processos. Trata-se, contudo, de múltiplas representações da realidade, isto é, vários modelos sobrepostos, mas dificilmente conectados pela lógica científica disciplinar. Nesse contexto da complexidade organizacional, o pensamento agroecológico fundamentado no paradigma sistêmico estabelece inter-relações entre o sistema de práticas sociais de agricultura (econômicas, simbólicas e políticas), o sistema cognitivo (os esquemas representacionais de natureza) e o sistema de objetos (as geobiocenoses) para compreender o agroecossistema inserido hologramaticamente em uma formação sócio territorial, cuja expressão sensível e, portanto, subjetiva materializa-se na paisagem.

Quanto mais complexos forem os comportamentos, mais os sistemas manifestarão a flexibilidade adaptativa em relação ao ambiente; a flexibilidade adaptativa do comportamento vai exprimir-se no desenvolvimento de estratégias heurísticas, inventivas, variáveis, que substituirão os comportamentos programados de 
forma rígida; o desenvolvimento das estratégias supõe o desenvolvimento interno dos dispositivos auto organizacionais (MORIN, 2011) Portanto, o desenvolvimento de estratégias heurísticas tornadas aptas para encarar várias estratégias possíveis para criar condições sustentáveis de vida, vai permitir a emergência de liberdades que poderão institucionalizar-se e começar a constituir um dos elementos da auto-organização das sociedades humanas.

\section{METODOLOGIA}

A discussão sobre o pensamento de complexidade e o estudo multicascos neste artigo, foca em várias áreas-chave que destacam aspectos em que o pensamento de complexidade envolve uma tomada de decisão em pesquisa. Trata-se de causalidade, estabelecimento de limites e localização do pesquisador, com base nas principais áreas de discussão da pesquisa de estudo de caso considerada por Gomm, Hammersley e Foster (2000). A maneira pela qual o estudo de caso pode ser adotado como uma abordagem metodológica relacionada à complexidade requer uma reflexão cuidadosa, pois a complexidade oferece o potencial de repensar métodos e estratégias comuns de pesquisa como resultado de sua base ontológica e epistemológica específica, influenciando a pesquisa, projeto, métodos e técnicas analíticas ou interpretativas que possam ser consideradas. Para cada elemento da discussão, foram ilustrados princípios considerados com referência a uma parte de uma pesquisa de estudo de caso realizada usando a perspectiva do pensamento sobre complexidade descrita anteriormente neste artigo.

Esta pesquisa é de natureza qualitativa, nesse tipo de pesquisa o significado é construído socialmente por indivíduos em interação com o próprio mundo. Sendo assim, existem várias construções e interpretações da realidade que estão em fluxo e que mudam ao longo do tempo (MERRIAM, 2002). Em relação ao delineamento da pesquisa, trata-se de uma pesquisa exploratória e descritiva. Estudos exploratórios visam proporcionar maior familiaridade com o problema, com vistas a torná-lo mais explícito (GIL, 2019). Estudos descritivos têm como objetivo principal analisar com exatidão fatos e fenômenos de determinada realidade e estabelecer relações entre as variáveis estudadas (TRIVIÑOS, 2007). 
A coleta de dados para este estudo multicascos ocorreu ente janeiro e março de 2020 e envolveu o Projeto RECA, o Assentamento Padre Ezequiel e a SEAGRI. Foram realizadas pesquisas por dados primários e secundários, observação não participante e 5 entrevistas em profundidade realizadas com 1 representantes da SEAGRI, 1 representante do Assentamento Padre Ezequiel, 3 representantes da Associação dos Pequenos Agrossilvicultores do Projeto RECA e Cooperativa Agropecuária e Florestal do Projeto RECA.

A análise dos dados coletados se deu por meio da análise de conteúdo. $\mathrm{Na}$ primeira fase houve a organização do material a partir de uma leitura profunda, que proporcionou a definição das unidades de registro, unidades de contexto e categorias. As unidades de registro frequentemente são palavras, frases e orações dentro do texto examinado. Já as unidades de contexto situam as citações no contexto da mensagem, o que geralmente dá origem às categorias. A segunda fase ocorreu a partir da codificação dos documentos em função das unidades de registro, unidades de contexto e categorias. A última fase consistiu no tratamento dos dados brutos em algo significativo para os objetivos da pesquisa, o que envolveu inferências a partir da confrontação sistemática do material com ele mesmo e com teorias de suporte (BARDIN, 2011).

\section{RESULTADOS E DISCUSSÕES}

A discussão sobre a agroecologia precisa tratar da complexidade do funcionamento dos agroecossistemas, para permitir o desenvolvimento não só da agricultura, mas também de todos os seres que habitam a terra. Aprofundar esse debate em relação aos agricultores de agroecológicos de Rondônia expõe as diferentes realidades que enfrentam, assim como os possíveis arranjos socioeconômicos que podem surgir em decorrência da região que se instalaram ou do período que imigraram para o estado. Rondônia recebeu migrantes vindos de todos os estados do país. A ocupação desordenada gerou articulações, implicações, e interdependências das realidades socioambientais, as quais foram analisadas pela lente teórica do pensamento complexo de Edgar Morin.

\section{Projeto RECA}


O Projeto RECA (Reflorestamento Econômico Consorciado e Adensado) realiza uma proposta produtiva agroflorestal, baseada no associativismo e na valorização da floresta, como alternativa ao desmatamento. Embora, o distrito de Nova Califórnia faça parte do município de Porto Velho-RO, encontra-se à $360 \mathrm{~km}$ da capital e a $150 \mathrm{Km}$ da capital do Acre, Rio Branco. A ocupação da área iniciou-se em 1986 a partir do assentamento demarcado pelo INCRA, onde as terras eram demarcadas e entregues as famílias as quais eram pressionadas a derrubarem a floresta. Com o trabalho de desbravar as terras, ficaram expostos à malária, além disso perceberam que o solo não era próprio para as culturas tradicionais das regiões sul e sudeste, como arroz, feijão, milho e soja, além da dificuldade de comercializar sua produção. Outro motivo que prejudicava os agricultores era a questão do litígio entre os estados de Rondônia e Acre, por ser uma zona em disputa, nenhum dos dois estados investia em infraestrutura básica para atender a região (RECA, 2020a).

Devido a estes problemas, os agricultores, juntaram-se com os seringueiros, povo mais antigo na região, e começaram a discutir formas alternativas para melhorar as condições de vida. Ao juntar os conhecimentos de organização e cooperação dos povos vindos de outras regiões do país com os conhecimentos dos povos da região, sobre a floresta, iniciou-se discussões sobre um projeto para a implantação de SAF's (Sistemas Agroflorestais) com plantas nativas.

Após discussões, o projeto, foi elaborado e apresentado aos governos do Acre e Rondônia, porém não houve adesão por parte dos gestores dos respectivos estados. Então apresentaram o projeto ao Bispo do Acre, Dom Moacyr Grech, um dos criadores da Comissão Pastoral da Terra (CPT), o qual decidiu apoiar os agricultores, enviando o projeto ao Centro de Estatística Religiosa e Investigações Sociais (CERIS), no Rio de Janeiro. Após o CERIS avaliar e reformular o projeto junto aos produtores, enviou o projeto a uma organização não governamental holandesa chamada CEBEMO. Com a aprovação do projeto, em fevereiro de 1989, a associação foi criada para receber os primeiros recursos para implantação de 200 hectares de SAF's, onde foram plantadas: Pupunheira, Cupuaçuzeiro e Castanheira. Em junho de 2006, devido ao impeditivo de associações comercializarem os produtos, segundo a legislação brasileira, houve a necessidade de fundar a cooperativa (RECA, 2020b).

Fazendo um paralelo da realidade enfrentada com o pensamento complexo proposto por Edgar Morin, verificou-se que o princípio dialógico tem acompanhado o 
Projeto RECA desde o início, pois em meio a uma política de assentamento, cujo o objetivo era desmatar, para garantir sua área, em uma zona de litígio, que não fornecia a estrutura básica, um solo diferente ao que estavam acostumados, levou os agricultores a observarem outra realidade, os moradores mais antigos, as espécies nativas. Duas realidades antagônicas que se chocaram, mas que foram essenciais para desenvolvimento de novas competências. Essas novas competências, por sua vez culminaram no princípio autogerativo, cujo os agricultores passaram a manejar as culturas tradicionais, fazendo desses produtos, sua marca, seu modo de vida.

Os SAFs, projeto idealizado pelos agricultores e a CPT, que posteriormente recebeu incentivos da CEBEMO, foram reflexos do princípio hologramático, onde se passou a enxergar que todas as diferenças fazem parte de um todo e a aceitação que fazem parte desse todo e são reflexo do ambiente e de suas escolhas, foi determinante para se firmarem na região, mesmo numa zona disputada entre dois estados. O reconhecimento que são uma unidade, e que essa unidade é responsável por tudo que acontece com ela mesma. As interdependências seguiram até culminarem na criação da cooperativa, foi praticamente uma interação entre os três princípios propostos pelo pensamento complexo.

Hoje, o Projeto RECA conta com 264 associados e 144 cooperados. Os associados recebem assistência técnica e treinamentos enquanto os cooperados são aqueles que podem comercializar seus produtos. Para se tornar associado ao projeto, o agricultor deve possuir, no mínimo, 2 hectares de terra e ter concluído um ano de acompanhamento pela equipe técnica para se adequar às exigências de manejo da produção (RECA, 2020b).

É importante frisar que dos 144 cooperados, 40 agricultores possuem selo de produção orgânica adquirido pela Certificação por Auditoria do Instituto Biodinâmico de Desenvolvimento Rural (IBD). Esse mesmo grupo de agricultores são responsáveis pelo Sistema de Controle Interno (SCI) para o acompanhamento da produção. Os produtores orgânicos e agroecológicos certificados se reúnem em reuniões bimestrais para discutir tanto as questões produtivas quanto organizacionais. Atualmente, não são todos os produtores associados ao Projeto RECA que fazem parte do grupo dos produtores orgânicos e agroecológicos, mas espera-se aumentar o número de participantes por meio do incentivo à transição agroecológica e do resgaste do 
conhecimento tradicional com a adoção de práticas alternativas que propiciem uma produção mais sustentável e saudável (RECA, 2020b).

A questão da certificação orgânica ainda traz muitos debates. Existem diferenças entre o orgânico e o agroecológico. Embora o Projeto RECA tenha se consolidado pela agroecologia, ainda há famílias que possuem práticas mistas referente à agricultura tradicional e à agroecológica. A certificação orgânica além de ser uma maneira de conquistar consumidores mais conscientes em busca de uma alimentação saudável, também é uma forma de fortalecer o princípio hologramático. Pois a certificação orgânica não se trata somente da preocupação de uma propriedade, mas sim das outras propriedades ao redor. Mesmo que uma propriedade não utilize agrotóxicos, caso seus vizinhos utilizem, o agricultor não receberia a certificação. Percebe-se que é uma parte que está no todo e que esse todo, no caso as outras propriedades, compõem o sistema complexo, sendo a correlação entre eles inevitável.

Outra característica importante é o potencial das propriedades serem agroecológicas e orgânicas, ou seja, produzirem seu produto sem pesticidas além de seguirem práticas de manejo respeitando a socio biodiversidade. É fundamental trabalhar com o princípio hologramático juntamente com todos os associados, pois aumentando a consciência de que todos fazem parte do mesmo sistema complexo e que podem ser beneficiados com a compreensão disso, facilita decisões futuras em prol da comunidade.

O princípio autogerativo é observado no Projeto Concretizar, financiado pelo Fundo Amazônia, os plantios de SAF's do RECA, abrangem mais de 20 diferentes espécies frutíferas e madeireiras, como também medicinais. E destas outras espécies, algumas já estão iniciando a produção: tais como a bacaba, andiroba, copaíba, sangue de dragão, rambutã, seringa e outros. As atividades executadas em subprojetos envolvem análise do solo, preparação das áreas onde serão plantadas as mudas, produção de mudas em viveiros locais existentes nas propriedades atendidas pelo projeto, plantio das áreas e manutenção das áreas plantadas.

Neste caso verifica-se que o produto é produtor de quem o produziu, em outras palavras, os agricultores plantam o que mais se adapta ao solo e criam mercado consumidor para isso. O plantio de rambutã exemplifica bem isso, a fruta asiática se adaptou as condições climáticas da região e ao manejo agroecológico dos agricultores, a 
partir disso, eles lançaram o produto no mercado e tem obtido retornos satisfatórios por parte dos consumidores. O Projeto RECA é um dos maiores produtores do Brasil.

Ocorre fortalecimento institucional por meio do aumento da capacidade técnica de seus associados e lideranças, envolvendo eventos de intercâmbio sobre implantação e manejo de SAFs e boas práticas de produção e armazenamento de produtos da socio biodiversidade, com agroextrativistas experientes da região atendida. Já a assistência técnica e extensão rural abrange as atividades dos técnicos e de jovens formados na Escola Família Agrícola Jean Pierre Mingan, fundada em 2009, e frequentada por filhos de pequenos agricultores da região onde atua a Associação RECA (RECA, 2020b).

Quando se fala de fortalecimento institucional, se fala de fortalecimento do princípio hologramático. Todo o envolvimento entre técnicos e associados é um auto reforço de que todos mesmo em sua individualidade fazem parte da mesma realidade. Neste caso, em especial, existe uma Escola Família Agrícola (EFA). Nesta unidade educativa, os filhos dos agricultores adquirem conhecimento para aplicarem em suas propriedades ou muitas vezes até na agroindústria do RECA. Além de possuírem uma grade especial de disciplinas, voltadas para sua realidade no campo, os alunos passam por três tipos de estágios, estágio social, estágio vegetal e estágio animal. Tudo isso para ampliar a visão de mudo do aluno e conseguir retê-lo no meio rural. Estratégia que tem funcionado.

Com essas práticas, a produção do RECA supera mais de um milhão de quilos de frutos em uma safra, mais de 350.000 quilos de polpa de cupuaçu, 100.000 quilos de sementes secas e fermentadas, 40.000 quilos de manteiga de cupuaçu, 31.500 latas de castanha, 50.000 quilos de óleo de castanha, mais de 256.500 hastes de pupunha, cerca de 72.000 quilos de palmito beneficiado, 186.000 quilos de polpa e 320.000 quilos do fruto de açaí, além da comercialização em torno de 30.000 quilos de sementes de pupunha (RECA, 2020a). Autossuficiência e consolidação no mercado são características do RECA, proveniente de princípios dialógicos, autogerativos e hologramáticos.

\section{Assentamento Padre Ezequiel}

O Assentamento Padre Ezequiel se localiza no município de Mirante da Serra, a cerca de $388 \mathrm{~km}$ da capital Porto Velho. A fazenda Urupá, onde o assentamento se encontra, foi alvo de três assentamentos do MST. Inicialmente em 1996 foram 
assentadas 323 famílias do Assentamento Palmares, logo depois foi criado o Assentamento Margarida Alves com 208 famílias assentadas, ambos no município de Nova União e em 2001 o assentamento Padre Ezequiel com 200 famílias no Município de Mirante da Serra.

A organização do assentamento Padre Ezequiel foi definida em agrovilas, cuja unidade produtiva em forma de raio de sol, permitiu que as moradias ficassem mais próximas, com mais contato entre as famílias. No início se praticava a produção de alimentos básicos para alimentação da família, com venda do excedente, havia plantações de arroz, feijão, milho, batata, mandioca, café e cacau. Os assentados criavam animais como galinhas caipiras, suínos, cachorros, gatos e após acessarem o Programa Nacional da Agricultura Familiar (PRONAF), que foi oferecido como financiamento das ações produtivas aos assentados, compraram bovinos para iniciar a criação (SOUZA, 2017).

Das famílias assentadas, houve um pequeno grupo, que a partir das orientações da organização produtiva do MST, resolveram, trabalhar com produção de alimentos sem agrotóxico. Tudo começou a partir das formações que o MST disponibilizava no acampamento e das formações oferecidas pela Diocese de Ji-Paraná, que por meio de um convenio com uma instituição europeia, oferecia formação em agroecologia.

Trazendo esses acontecimentos para a lente da complexidade se identifica o princípio dialógico, onde duas realidades que se opõem, mas que também se complementam. O assentamento possuía várias famílias, o intuito era de aproxima-las, fazer com que trabalhem juntas, porém houve um grupo que se voltou para as culturas tradicionais e criação de gado, enquanto outro grupo optou por uma produção de alimentos agroecológicos. Não houve uma separação, mas uma distinção de pensamentos e ações dentro de uma mesma unidade. Os agricultores que optaram pelo caminho agroecológico passaram a viver de acordo com o princípio autogerativo. A produção do agricultor passou a ser sua identidade e permitiu o alcance de novos atores na sua realidade, no caso, sua incursão no Projeto Terra Sem Males.

A partir do Projeto Terra Sem Males, uma ação participativa construída com a iniciativa da Diocese de Ji-Paraná, por intermédio da CPT e do então Projeto Padre Ezequiel, que, juntamente com a Agência Regional de Comercialização (TUCUMÃ), resolveram encarar o desafio de construir uma agricultura com base ecológica (SOUZA, 2017). 
As famílias, com o devido apoio, buscaram conhecimentos em agroecologia visando à mudança de conduta na agricultura e a difusão de conhecimentos pela troca de experiência. Estes debates revelaram a necessidade de acompanhamento técnico com base na produção agroecológica, olhando a produção de alimentos com responsabilidade social e ambiental. Em 2003, receberam apoio financeiro da entidade inglesa Agencia Católica para o Desenvolvimento (CAFOD), sendo que o recurso ficou sobre a responsabilidade de execução da CPT (ASEENTAMENTO PADRE EZEQUIEL, 2020).

O fato interessante nessa busca pelo o aperfeiçoamento do conhecimento agroecológico foi identificar o princípio hologramático e posteriormente o princípio autogerativo. Trata-se de pessoas que compartilhavam a mesma realidade, e que por meio de seus debates, levaram à necessidade de acompanhamento técnico, ou seja, a partir de uma dificuldade surgiu uma organização em busca de uma solução.

Como resultado do projeto pela formação para a prática agrícola com ênfase na produção de alimentos em sistemas agroflorestais, do Assentamento Padre Ezequiel, apenas uma família foi beneficiada, porém, outras famílias aderiram ao não uso de agrotóxico. Os agricultores passaram a produzir usando técnicas alternativas, com uso de caldas, biofertilizantes, compostagens, rotação de culturas, pousio, dentre outras técnicas sugerida pelos executores do projeto.

A partir dessa iniciativa, começou a produção e debate agroecológico com outras famílias que resultou na criação em 2012 de uma feira denominada Feira de Produção da Agricultura Camponesa (FEPAC). Ao todo, a feira era composta por 26 famílias espalhadas por todo o município, do assentamento 12 famílias aderiram à feira. Com a feira, foi criada na cidade uma expectativa de alimentação diferenciada, sem agrotóxico e com contato direto dos consumidores com os produtores, tinha um formato de caixa único. Nesse formato uma ficha era impressa com o nome de todos os feirantes, sendo que o consumidor, na sua primeira compra, recebia a ficha e a cada banca que passava, era acrescentada na ficha o valor de sua compra na frente do nome do feirante que lhe vendia o produto (SOUZA, 2017).

Neste caso, ressaltou-se o princípio hologramático, pois independentemente do benefício, as outras famílias se identificaram com a proposta agroecológica e formaram um grupo para troca e disseminação de ideias, e que, posteriormente, resultou no princípio autogerativo, com a criação da FEPAC. Depois da criação da feira, retoma-se 
o princípio hologramático com o sistema "caixa comum". Por meio desse sistema houve a inclusão do consumidor à complexidade sistêmica da agroecologia.

Apesar dos desafios, a feira continua acontecendo, num formato menor, com 15 famílias, sendo 08 do assentamento, o sistema de caixa comum continua. Recebe para sua organização auxílio do Instituto Padre Ezequiel Ramin juntamente com MST e MPA. Em 2017, teve início pelo Governo Estadual a execução de uma chamada pública de ATER em agroecologia que ainda em 2017 foi encerrada por falta de repasse de recurso pelo Governo Federal, que era o financiador. De 2014 a 2016, foi executado no assentamento também um programa Chamado Terra Forte, que visava o fortalecimento da cadeia produtiva do leite e do cacau, por meio da implantação agroindústrias para beneficiamento de derivados de leite e cacau. Uma equipe do programa percorreu a região por alguns anos organizando as famílias, porém, por falta de repasse de recursos o programa teve que ser encerrado. Com a organização da Cooperativa Agrícola de Produção, Comercialização e Gestão dos Recursos Naturais do Assentamento Padre Ezequiel (COOPERNAPE), foram organizadas a comercialização da produção e o manejo florestal da reserva (ASEENTAMENTO PADRE EZEQUIEL, 2020).

A falta de recursos embora tenha afetado alguns projetos, serviu como precursor para a criação da cooperativa. Nota-se integração do princípio dialógico, com o princípio autogerativo. A adversidade pelo fim dos projetos levou os agricultores a se organizarem para vender sua produção. Nota-se que há um esforço para que todos os agricultores compreendam que fazem parte do mesmo contexto $\mathrm{O}$ ciclo começa a evoluir quando chega ao princípio hologramático. Por isso a interação e a retroação dos princípios do pensamento complexo são fundamentais para compreender a socio biodiversidade proposta pela agroecologia.

\section{Secretaria de Agricultura}

Embora nos dois casos anteriores, foram analisadas áreas de manejo agroecológico, é importante analisar as políticas públicas direcionadas à Agroecologia com a mesma lente teórica, o pensamento complexo. Antes de avançar sobre a visão da SEAGRI, é necessário compreender o Plano Nacional de Agroecologia e Produção Orgânica (PLANAPO), um dos principais instrumentos da Política Nacional de Agroecologia e Produção Orgânica (PNAPO) e o cenário que atuam. Esse cenário envolve uma cronologia apresentada na figura 01, Linha do Tempo da Política Federal 
para a Agroecologia e Produção Orgânica. Nota-se que o PLANAPO, não foi uma medida isolada, juntamente foram criados o Programa ECOFORTE, para o fortalecimento das redes de agroecologia; o Programa de Redução do Uso de Agrotóxicos (PRONARA); e nesse período houve editais de chamada para ATER, Pesquisa, Educação e Extensão. Vale ressaltar que houve ação sinérgica entre órgãos do Governo, por exemplo, o Programa de Aquisição de Alimentos (PAA), criado em 2003 e a lei 11.947 de 2009, que introduziu a agricultura familiar no Programa Nacional de Alimentação Escolar (PNAE).

Figura 01- Linha do Tempo da Política Federal para a Agroecologia e Produção

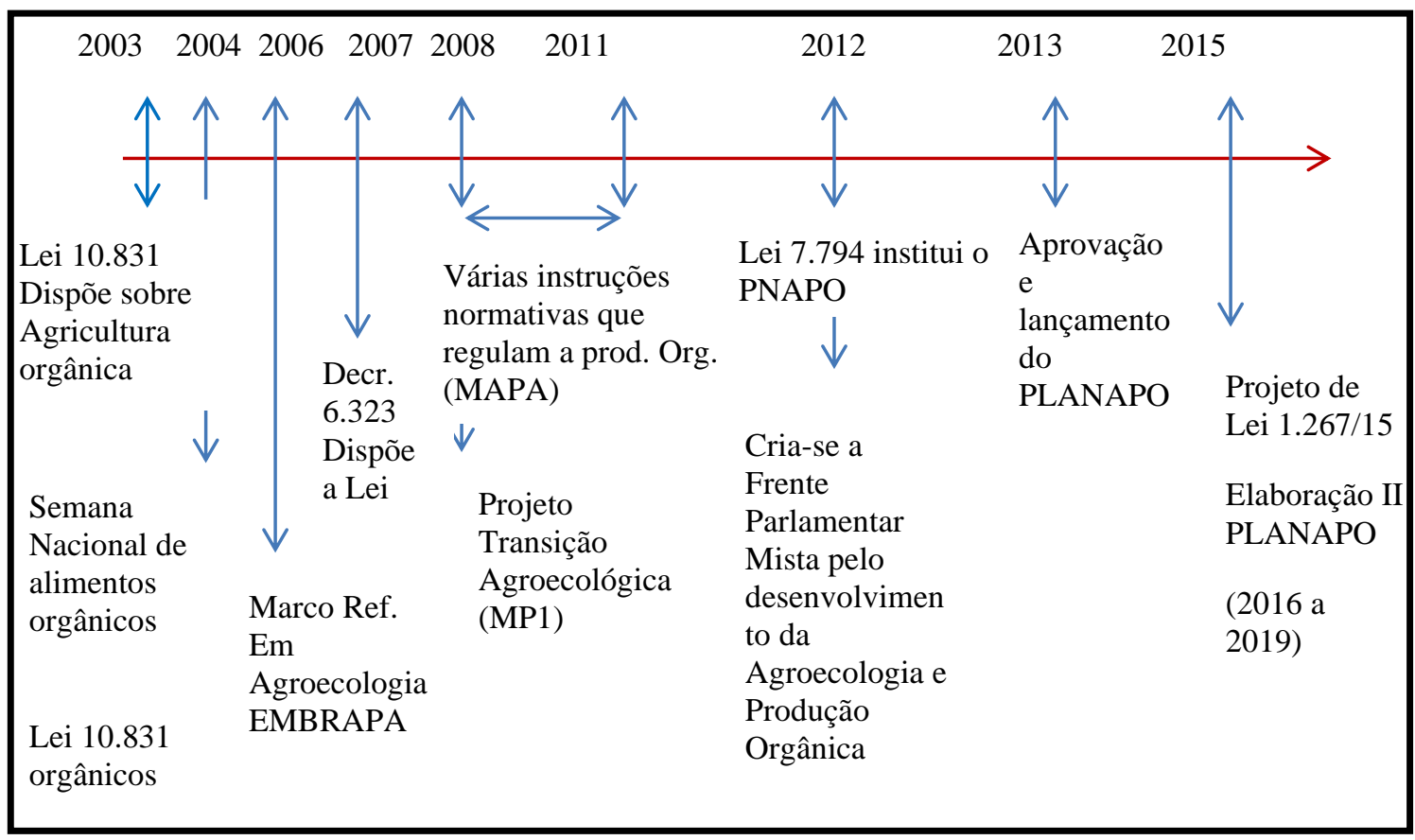

Fonte: EMATER, 2015

\section{Orgânica}

Em Rondônia, somente em 2011 com a lei estadual $n^{\circ} 2.588$ iniciou-se alguns esforços em relação à Agroecologia, com a criação do Programa Estadual de Agroecologia e Incentivo à Produção Orgânica. Em 2012, por meio da lei estadual complementar $\mathrm{n}^{\mathrm{o}} 655$ houve a criação do Fundo de Desenvolvimento e Fortalecimento da Agricultura, do qual tem como um dos objetivos o fortalecimento da agricultura familiar pautada pelos princípios da Agroecologia e da socio economia solidária. Neste mesmo ano criou-se a Câmera Técnica de Agroecologia. Em 2015, com o decreto $\mathrm{n}^{\circ}$ 19.895, foi instituída a Política Estadual de Agroecologia e Produção Orgânica do Estado de Rondônia - PEAPO/RO, com o objetivo de promover, integrar, articular e 
adequar políticas, programas e ações indutoras da transição agroecológica e da produção orgânica e de base agroecológica. No mesmo ano, a lei $n^{\circ} 3.566$ instituiu a Semana Estadual de Incentivo à Agroecologia, e Câmera Técnica de Agroecologia passou a se chamar Câmera Setorial de Agroecologia.

A princípio essa política funcionou até meados de 2017 , o que justifica a falta de repasses, retratada no segundo estudo de caso analisado. Conforme um dos entrevistados da SEAGRI, a Câmera Setorial de Agroecologia não teve o apoio considerado das ONGs e das instituições participantes, além da dificuldade de reunir todos os participantes da ATER.

\begin{abstract}
O projeto Padre Ezequiel, que agora virou Instituto trabalha saúde agricultura questão de cidadania né, a vinculação da saúde com a agricultura criou uma discussão da homeopatia, isopatia, fitoterapia né e inclusive a rádio estesia que ele trabalha com isso no campo e a discussão da agricultura orgânica dos cursos lá foi estimulada com uma política do Governo Federal para ações do PRONAF voltadas a agroecologia. Então foram três anos que a gente pôde desenvolver um trabalho muito legal lá, conseguimos gastando correto, 97\% do recurso que a gente tinha, a gente utilizou fazendo as ações. O problema era que tinha um monte de dados e a gente saiu com um monte de informação detectado mais de 1.500 produtores nas diferentes formas de produção e de uma base para um plano, que junto com os conhecimentos do Padre Ezequiel das instituições daria para continuar isso, mas daí foi uma questão de parceria... que não aconteceu (SEAGRI, 2020).
\end{abstract}

Por meio da declaração feita pelo entrevistado verificou-se que havia potencial para dar continuidade ao trabalho desenvolvido. Conseguiram identificar o perfil agroecológico em 1.500 agricultores, embora a falta de investimentos públicos prejudicou o projeto, se as parcerias com as ONGs tivessem continuado, haveria a possibilidade de consolidação. Ao comparar o que ocorreu no Assentamento Padre Ezequiel com o Projeto RECA, verificou-se que as organizações não governamentais são importantes, afinal, no RECA foi o financiamento da holandesa CEBEMO que impulsionou o projeto.

Houve também outro diferencial, o princípio hologramático. Os agricultores do distrito de Nova Califórnia possam um senso de pertencimento e união maior, a agroecologia aplicada às plantas nativas da região foi a maneira que encontram para sobreviver. Enquanto para os agricultores do município de Mirante da Serra optaram por um manejo agroecológico de cultura tradicional. Era mais uma questão ideológica do que sobrevivência. De tal maneira que outros assentados não aderiram a proposta. Faltou o reconhecimento de que as partes fazem parte de um todo. Por consequência, 
não chegaram no princípio autogerativo, pois não tinham um produto que era referência de seu modo de vida, de sua comunidade. Embora a COOPERNAPE, tenha sido criada um tempo depois, para atender os agricultores que persistiram nos agroecológicos, ainda é uma iniciativa pequena, visto que o potencial de participação de outros produtores é muito maior.

Para o entrevistado, a Agroecologia, ainda não "vingou" devido à diferentes visões dos principais atores. Há muito mercado para a compra de orgânicos e agroecológicos, porém a SEAGRI tem que divulgar mais esses produtos e o agricultor tem que entender que a compra institucional, voltada para o PAA e PNAE, por exemplo, serve como introdução para compreenderem o mercado. Por meio desses programas eles tem que perceber que deve haver qualidade, regularidade para atender as necessidades de seus consumidores. Assim, eles conseguiriam permanecer em sua atividade agrícola, sem depender de políticas do governo, pois agricultura familiar e agroecologia podem não ser prioridades para os governantes, logo, os produtores podem ser duramente afetados.

Nesse fragmento se percebe a importância de compreender o princípio dialógico, duas lógicas antagônicas que se complementam. Há uma série de debates sobre o papel das políticas públicas e as políticas de mercado, não é questão de uma se sobrepor a outra, mas entender que uma leva a outra, e que ambas são importantes para a manutenção da agroecologia no estado.

Outro aspecto que o entrevistado chama atenção é a confusão de orgânico, tradicional e agroecológico:

\begin{abstract}
Orgânico não é tradicional, tá, isso é um erro. Tradicional é quando dentro de áreas de povos tradicionais, por exemplo, a castanha, tem um histórico, uma cultura, é a própria reciclagem da floresta, dos processos, fazem a incrementação da produção, então você não utiliza produtos extras, inclusive tem um nome específico para isso dentro do processo da certificação orgânica para esses casos, o RECA tem isso. O Projeto RECA, eles têm esse extrativismo. E o que a gente quer é justamente quebrar essa história, tradicional. Se quer ser agroecológico tem que ter técnicas e manejos, para certificar precisa apresentar o plano de manejo orgânico. O que é proibido é o produtor ter um produto agroecológico e dizer que ele é orgânico. Ele pode vender como agroecológico, se usa técnicas e manejos da agroecologia, e agora certificação orgânica é só através do MAPA. Existem estados dando certificação orgânica, mas não é o caso de Rondônia (SEAGRI, 2020).
\end{abstract}

É preciso esclarecer a comunidade essa diferença entre orgânico, agroecológico e tradicional. A agroecologia é uma ciência dedicada ao estudo das relações produtivas 
entre homem-natureza, com o objetivo sustentabilidade ecológica, econômica, social, cultural, política e ética. Sua proposta se baseia na pequena propriedade, na mão de obra familiar, em sistemas produtivos complexos e diversos, adaptados às condições locais e em redes regionais de produção e distribuição de alimentos.

Já a essência filosófica do orgânico consiste num desprezo absoluto por tudo que tenha origem na indústria química. Pode se estender à produção agrícola e pecuária, em pequenas e em grandes propriedades. Em grandes propriedades no Brasil, se encontram os casos da Fazenda Malunga, no Distrito Federal, produtora de hortaliças; e da Fazenda São Francisco, no estado de São Paulo, proprietária da marca Native, que produz açúcar. Seus produtos são orgânicos, mas não são agroecológicos. Há casos, como as 40 propriedades certificadas filiadas ao Projeto RECA, em que os produtos são orgânicos e agroecológicos, pois além de não usarem agrotóxicos, seguem os princípios da agroecologia.

Existem casos que uma propriedade pode seguir os princípios da agroecologia e produzir produtos sem agrotóxicos, porém, não cumprem todas as determinações do Decreto Federal no 6.323 de 27 de dezembro de 2007. Uma dessas determinações, por exemplo, é a exigência de uma equipe oficial de auditores para realizar a avaliação da propriedade, para verificar a conformidade com a regulamentação oficial. O RECA possui a Certificação por Auditoria do Instituto Biodinâmico de Desenvolvimento Rural (IBD), porém isso tem um custo de cerca de 11 a 15 mil Reais por ano, valor impraticável para uma pequena propriedade.

Enquanto os produtos provenientes de extrativismo, correspondem à coleta de produtos retirados da natureza, sem um plano de manejo para plantio da espécie. $\mathrm{O}$ exemplo mais expressivo no estado é a coleta de Castanha do Brasil.

Outro ponto fraco identificado foi a dificuldade de reconstruir o processo de aprendizagem para produção e comercialização de agroecológicos. O entrevistado cita um exemplo recorrente da comunidade ribeirinha conhecida como Baixo Madeira. Muitas vezes o agricultor até recebe capacitação para produzir agroecológico, ele consegue melhorar a qualidade de seu produto, porém acaba vendendo sua produção com o mesmo preço de antes, pois o atravessador quer pagar o mesmo valor, ignorando o valor agregado. Um órgão que vem investindo nesse processo de aprendizagem é a Secretaria Municipal de Agricultura de Porto Velho (SEMAGRIC), cujo entrevistado 
ressaltou o número de ações que têm realizado para tentar entender e embasar um espaço ou uma política de comercialização para esses agricultores.

O trabalho que a SEMAGRIC exerce surgiu do princípio autogerativo da situação, ou seja, necessidade de se ter produtos agroecológicos para atender o mercado, porém, além da capacitação, é necessário buscar um canal de comunicação do produtor com o consumidor final, pois a figura do atravessador quebra o princípio hologramático, não ocorre a ideia de que todos fazem da mesma realidade.

Outra prática ressaltada é o que o Projeto RECA tem feito em relação ao reaproveitamento de restos de frutas que ficam nas máquinas de sua agroindústria, eles pegam esses resíduos e fazem compostagem. O composto é vendido para seus associados a um preço simbólico, só para manter a manutenção das máquinas utilizadas no processo de compostagem.

Neste caso se observa o princípio dialógico, onde surgiu o problema dos restos e da falta de destinação deles. As forças eram: manter a qualidade dos produtos, eliminando o que não está no padrão; e cumprir com a responsabilidade ambiental. $\mathrm{O}$ confronto entre essas dualidades culminou no princípio autogerativo, no caso, a ideia de trabalhar os resíduos na compostagem. E isso por sua vez levou ao princípio hologramático, onde o composto produzido é direcionado para os associados. O que saiu da terra na forma de fruto, volta na forma de composto orgânico.

Quando perguntado, sobre qual é a estratégia que a SEAGRI utilizará em relação à Agroecologia para os próximos anos, o entrevistado disse que uma das ações é valorizar o café orgânico. Segundo ele, o estado está interessado em possibilidades de entrada de recurso, e ajudar a vender o café orgânico vai trazer mais publicidade de para o trabalho da secretaria. Assim, com possíveis fomentos e parcerias, isso facilitaria a articulação de outros produtos agroecológicos.

Vale ressaltar que o estado de Rondônia tem modernizado a cafeicultura por meio de um conjunto de medidas políticas de desenvolvimento de pesquisas e assistência técnica, além de financiamentos, que tem contribuído para que o resultado da produção seja mais satisfatório aos agricultores, atraindo-os novamente a essa atividade. Além da participação dos agentes públicos e privados no desenvolvimento da atividade, o avanço técnico sobre áreas de práticas tradicionais, modificando a condição técnica do espaço, e inserindo mais agricultores familiares à lógica de mercado e aos interesses dos 
principais agentes, ou seja, expandindo a área de atuação do capital no estado (SILVA et. al, 2020).

Esse avanço técnico sobre áreas de práticas tradicionais, diz respeito sobre as medidas da SEAGRI sobre o plantio de café orgânico agroecológico. Os produtores de café orgânico consorciado com outras espécies seriam alguns agricultores do Projeto RECA, Cooperativa de Produtores Rurais Organizados para Ajuda Mútua (COOCARAM) e Cooperativa dos Agricultores Familiares da Amazônia (LACOOP).

A SEAGRI vivencia o princípio dialógico, trabalhando duas realidades existentes do cultivo do café, de um lado o crescimento do café Robusta Clonal, que tem posicionado o estado como um dos principais produtores, e de um lado o café orgânico agroecológico, proveniente de pequenos agricultores. Duas realidades, que se embatem, mas que a secretaria está utilizando para autogerar sua política em relação à agroecologia.

As informações e os fatos que emergiram das entrevistas constituem um mosaico interessante quando agrupados. O Quadro 01 apresentada um resumo dos resultados encontrados nas 3 instituições.

Quadro 01- Síntese das análises

\begin{tabular}{|c|c|c|c|}
\hline \multirow[b]{2}{*}{ Instituições } & \multicolumn{3}{|c|}{ Princípios da complexidade (Morin, 2011) e de Agroecologia (Caporal et al., 2009) } \\
\hline & Princípio Dialógico & Princípio Autogerativo & Princípio Hologramático \\
\hline \multirow{5}{*}{ Projeto RECA } & $\begin{array}{l}\text { Cultivo de espécies } \\
\text { nativas. }\end{array}$ & $\begin{array}{l}\text { Manejo de culturas tradicionais } \\
\text { como modo de vida. }\end{array}$ & $\begin{array}{l}\text { SAFs (Sistemas } \\
\text { Agroflorestais). }\end{array}$ \\
\hline & & Projeto Concretizar. & Certificação orgânica. \\
\hline & & & $\begin{array}{l}\text { Associados em prol da } \\
\text { comunidade. }\end{array}$ \\
\hline & & & $\begin{array}{l}\text { Aumento da capacidade } \\
\text { técnica de seus associados. }\end{array}$ \\
\hline & & & $\begin{array}{l}\text { Aumento da capacidade } \\
\text { técnica de seus associados. }\end{array}$ \\
\hline \multirow{4}{*}{$\begin{array}{l}\text { Assentamento } \\
\text { Padre Ezequiel }\end{array}$} & $\begin{array}{l}\text { Agricultores } \\
\text { divididos entre } \\
\text { culturas tradicionais } \\
\text { e produção de } \\
\text { alimentos } \\
\text { agroecológicos. }\end{array}$ & Projeto Terra Sem Males. & $\begin{array}{l}\text { Aperfeiçoamento do } \\
\text { conhecimento } \\
\text { agroecológico. }\end{array}$ \\
\hline & & $\begin{array}{l}\text { Em 2003, receberam apoio } \\
\text { financeiro da CAFOD. }\end{array}$ & $\begin{array}{l}\text { Outras famílias aderiram } \\
\text { agroecológicos. }\end{array}$ \\
\hline & & $\begin{array}{l}\text { Em } 2012 \text { Feira de Produção da } \\
\text { Agricultura Camponesa } \\
\text { (FEPAC). }\end{array}$ & \\
\hline & & $\begin{array}{l}\text { Cooperativa Agrícola de } \\
\text { Produção, Comercialização e }\end{array}$ & \\
\hline
\end{tabular}




\begin{tabular}{|c|l|l|l|}
\hline & & $\begin{array}{l}\text { Gestão dos Recursos Naturais } \\
\text { do Assentamento Padre } \\
\text { Ezequiel (COOPERNAPE). }\end{array}$ & \\
\hline \multirow{3}{*}{ SEAGRI } & $\begin{array}{l}\text { Políticas públicas e } \\
\text { as políticas de } \\
\text { mercado. }\end{array}$ & Capacitação SEMAGRIC. & $\begin{array}{l}\text { A figura do atravessador } \\
\text { quebra o princípio } \\
\text { hologramático. }\end{array}$ \\
\cline { 2 - 5 } & $\begin{array}{l}\text { Resíduos do RECA e } \\
\text { da falta de destinação } \\
\text { deles. }\end{array}$ & $\begin{array}{l}\text { Ideia do RECA de trabalhar os } \\
\text { resíduos na compostagem. }\end{array}$ & $\begin{array}{l}\text { Composto produzido a } \\
\text { partir dos resíduos é } \\
\text { direcionado para os } \\
\text { associados do RECA. }\end{array}$ \\
\hline
\end{tabular}

Fonte: Dados da pesquisa

Observando o Quadro 01, que compara os achados nas 3 instituições visitadas de acordo com os princípios do pensamento complexo, percebe-se que que existe uma sequência. Inicia-se com o princípio dialógico que apresenta duas realidades antagônicas para a comunidade. Do embate dessas realidades surge o princípio autogerativo, em que realidades são criadas com o intuito de resolver um problema. Enquanto ao princípio hologramático surge ao final de um processo para consolidar a criação proveniente do princípio autogerativo. Uma observação importante, é que as ações que não alcançam o princípio hologramático, não se consolidam.

\section{CONSIDERAÇÕES FINAIS}

Analisar o desenvolvimento da agroecologia, juntamente com as crenças, conhecimentos e práticas das coletividades, no estado de Rondônia utilizando-se do pensamento complexo, proposto por Morin (2011), trouxe uma outra perspectiva sobre as ações que tem sido realizada. O movimento agroecológico não pode ser descrito somente por dados quantitativos e pensamento cartesiano, pois sua evolução é "medida" por meio de relacionamentos, seja do agricultor com o grupo ou com o solo, do solo com meio ambiente, o meio ambiente com o agricultor, que por sua vez interage com o consumidor, que interage com outras instituições. É uma reação em cadeia onde todos estão interligados.

Os dois exemplos apresentados, o Projeto RECA e o Assentamento Padre Ezequiel, são exemplos de duas realidades diferentes. O primeiro, mais consolidado, em virtude do tempo, mas também devido, principalmente, à compreensão que todos associados fazem parte da mesma realidade em que o fruto de seu trabalho é reflexo de sua identidade. Enquanto o segundo, ainda está construindo sua identidade, recebendo ajuda do Instituto Padre Ezequiel e da CPT, buscando por sua emancipação econômica. 
Sobre os princípios do pensamento complexo, notou-se que há uma sequência, inicia-se com o dialógico, onde a comunidade, ou a secretaria, tem que lidar com duas realidades antagônicas. Do embate dessas realidades surge o princípio autogerativo, que, em muitas vezes, é uma solução de um problema. Enquanto ao princípio hologramático, este surge ao final de um processo para consolidar a criação proveniente do princípio autogerativo. As ações que não alcançam o princípio hologramático, não se consolidam. Assim com base nos dados observados se pode coordenar melhor as iniciativas futuras para constituir políticas públicas, projetos público-privados ou parcerias com o terceiro em benefício dos sistemas agroecológicos.

A SEAGRI, a medida do possível, procura conciliar as diferentes realidades de cada projeto, com uma política mais voltada ao agronegócio. Os esforços do setor de agroecologia têm sido preeminentes para que se estruture um plano de ação para atender toda a rede, já mapeada por relatórios técnicos internos. Verificou-se que os órgãos e instituições envolvidos é bem maior do que os que participaram nos dois casos ilustrados neste artigo, cabendo, nesta lacuna, exploração de novas realidades.

Em meio a essas iniciativas, surgem como potenciais atores institucionais, no âmbito federal, o Ministério da Agricultura Pecuária e Abastecimento (MAPA), Empresa Brasileira de Pesquisa Agropecuária (EMBRAPA), Comissão Executiva do Plano da Lavoura Cacaueira (CEPLAC), Instituto Nacional de Colonização e Reforma Agrária (INCRA), Fundação Banco do Brasil (FBB), Banco da Amazônia (BASA), Universidade Federal de Rondônia (UNIR), Instituto Federal de Rondônia (IFRO), Serviço Nacional de Aprendizagem Rural (SENAR), Instituto Nacional de Pesquisas na Amazônia (INPA), Agência Nacional de Vigilância Sanitária (ANVISA), Instituto Chico Mendes de Conservação da Biodiversidade (ICMBIO), Instituto Brasileiro do Meio Ambiente e dos Recursos Naturais Renováveis (IBAMA), Companhia Nacional de abastecimento (CONAB); no âmbito estadual Secretaria Estadual de Agricultura (SEAGRI), Entidade Autárquica de Assistência Técnica e Extensão Rural do Estado de Rondônia (EMATER-RO), Agência de Defesa Sanitária Agrosilvopastoril do Estado de Rondônia (IDARON), Secretaria de Estado Da Assistência e do Desenvolvimento Social (SEAS), Secretaria do Estado do Desenvolvimento Ambiental (SEDAM); e no âmbito municipal a Secretaria Municipal de Agricultura (SEMAGRIC) e a Secretaria Municipal de Meio Ambiente (SEMA) (EMATER, 2015). 
Os outros atores são as organizações sociais caracterizada pela Rede de Agroecologia Terra Sem Males, a qual é formada pela Comissão Pastoral da Terra (CPT), Cooperativa de Produtores Rurais Organizados para Ajuda Mútua (COOCARAM), Movimento dos Sem Terra (MST), Movimento dos Pequenos Agricultores (MPA), Movimento dos Atingidos por Barragens (MAB), Associação das Escolas Família Agrícola de Rondônia (AEFARO) e Escolas Família Agrícola (EFA’S). Além dos atores dessa Rede se reconhece os Povos Tradicionais, como Quilombolas, Seringueiros, Indígenas e Ribeirinhos; Associação dos Produtores Rurais de Cachoeira (APRUC); Centro de Estudos Rio Terra; Ação Ecológica Guaporé (ECOPORÉ); e Federação dos Trabalhadores Rurais Agricultores e Agricultoras Familiares do Estado (FETAGRO) (EMATER, 2015).

Vale ressaltar que o trabalho de capacitação e acompanhamento que a SEMAGRIC de Porto Velho vem desenvolvendo junto à 12 propriedades modelos de sistemas agroecológicos merecem ser pesquisado.

Como limitações para este estudo, conforme exposto, foram analisados apenas dois projetos dentro de um universo mais abrangente de possibilidades para a temática da pesquisa. Cabe o desafio às próximas pesquisas.

\section{REFERÊNCIAS}

ASSENTAMENTO PADRE EZEQUIEL. Entrevista II. [jan. 2020]. Entrevistador: Eliane Alves da Silva. Porto Velho-RO, 2020. 1 arquivo.mp3 (1h:26 min.).

AZEVEDO, R. A. B. Análise e descrição de sistemas agrícolas: teorias para não naturalização da agricultura. Revista Verde, v. 2, n. 2, p. 01-26, 2007. Disponível em: < https://webcache.googleusercontent.com/search?q=cache:PGLoPWr-

5wEJ:https://www.gvaa.com.br/revista/index.php/RVADS/article/download/40/40+\&cd $=4 \& \mathrm{hl}=\mathrm{pt}-\mathrm{BR} \& \mathrm{ct}=\mathrm{clnk} \& \mathrm{gl}=\mathrm{br}>$. Acesso em 02 abr. 2020.

BARDIN, L. Análise de conteúdo. São Paulo: Edições 70, 2011.

BRANDEMBURG, A.; BEZERRA, I.; GIORDANI, R. C. F. Soberania alimentar, desenvolvimento territorial e sustentabilidade: olhares e contextos. Guaju, v. 2, p. 2-13, 2016. Disponível em: <https://revistas.ufpr.br/guaju/article/view/49008>. Acesso em 02 abr. 2020.

BRASIL. Decreto Federal nº 6.323 de 27 de dezembro de 2007. Diário Oficial [da]

República Federativa do Brasil, Brasília, DF, 2007. Disponível em: < http://www.planalto.gov.br/ccivil_03/_Ato2007-2010/2007/Decreto/D6323.htm>. Acesso em 06 abr. 2020. 
BRASIL. Lei no 10.696, de 2 de julho de 2003. Diário Oficial [da] República Federativa do Brasil, Brasília, DF. 2003. Disponível em: < http://www.planalto.gov.br/ccivil_03/LEIS/2003/L10.696.htm>. Acesso em: 28 abr. 2019.

BRASIL. Lei Federal nº 10.831 de 23 de dezembro de 2003. Diário Oficial [da] República Federativa do Brasil, Brasília, DF, 2003. Disponível em: < https://www.gov.br/agricultura/ptbr/assuntos/sustentabilidade/organicos/legislacao/portugues/lei-no-10-831-de-23-dedezembro-de-2003.pdf/view>. Acesso em 06 abr. 2020.

BRASIL. Lei Federal nº 11.947 de 16 de junho de 2009. Diário Oficial [da] República Federativa do Brasil, Brasília, DF, 2009. Disponível em: < http://www.planalto.gov.br/ccivil_03/_Ato2011-2014/2014/Lei/L12982.htm>. Acesso em: 16 ago. 2020.

BRASIL. Lei Federal no 7.794 de 20 de agosto de 2012. Diário Oficial [da] República Federativa do Brasil, Brasília, DF, 2003. Disponível em: < http://www.planalto.gov.br/ccivil_03/_ato20112014/2012/decreto/d7794.htm\#: :text=1\%C2\%BA\%20Fica\%20institu\%C3\%ADda\%20 a\%20Pol\%C3\%ADtica,a\%20qualidade\%20de\%20vida\%20da>. Acesso em 06 abr. 2020.

CAPOAL, F. R.; COSTABEBER, J. A. PAULUS, G. Agroecologia: Matriz disciplinar ou novo paradigma para o desenvolvimento rural sustentável. In CAPOAL, F. R.; COSTABEBER, J. A. PAULUS, G. (Org.). Agroecologia uma ciência do campo da complexidade. Brasília, DF: Dos autores, 2009.

ENTIDADE AUTÁRQUICA DE ASSISTÊNCIA TÉCNICA E EXTENSÃO RURAL DO ESTADO DE RONDÔNIA (EMATER-RO). Agroecologia uma construção de saberes e poderes: palestra técnica. Porto Velho, 2015.

FLORIANI, D. Educação ambiental e epistemologia: conhecimento e prática de fronteira ou uma disciplina a mais?. Revista Pesquisa em Educação Ambiental, v. 4, n.2, p. 191-202, 2009. Disponível em: < http://www.periodicos.rc.biblioteca.unesp.br/index.php/pesquisa/article/view/6200 >. Acesso em 02 abr. 2020.

GIL, A. C. Como elaborar projetos de pesquisa. (6a. Ed.). São Paulo: Atlas, 2019.

GOLDELIER, M. O ideal e o material: pensamento, economias, sociedades. Paris: Fayard, 1984.

GOMM, R.; HAMMERSLEY, M.; FOSTER, P. Case study and generalization. In GOMM, R.; HAMMERSLEY, M.; FOSTER P. (Eds.). Case study method, London: Sage, 2000.

LEFF, E. Saber ambiental: sustentabilidade, racionalidade, complexidade, poder. 11 ed. Petrópolis: Vozes, 2011. 
MERRIAM, S. B. Introduction to qualitative research. Qualitative research in practice: examples for discussion and analysis, p. 3-17, 2002.

MORIN, E. O Método - 6 volumes. 1 ed. Porto Alegre: Editora Sulina, 2005.

MORIN, E. Introdução ao pensamento complexo. 4 ed. Porto Alegre: Editora Sulina, 2011.

REFLORESTAMENTO ECONÔMICO CONSORCIADO E ADENSADO (RECA). Quem somos. Disponível em: < http://www.projetoreca.com.br/site/quem-somos/> Acesso em 06 abr. 2020(a).

REFLORESTAMENTO ECONÔMICO CONSORCIADO E ADENSADO (RECA). Entrevista III. [mar. 2020]. Entrevistador: Eliane Alves da Silva. Nova Califórnia-RO, 2020(b). 1 arquivo.mp3 (40 min.).

RONDÔNIA. Decreto Estadual no 19.895, de 17 de junho de 2015. Diário Oficial [do] Estado de Rondônia, Porto Velho, RO. 2015. Disponível em: < http://www.diof.ro.gov.br/data/uploads/2015/06/Doe-_-17-06-2015.pdf>. Acesso em: 06 set. 2020.

RONDÔNIA. Lei Estadual no 2.588 de 28 de outubro de 2011. Diário Oficial [do] Estado de Rondônia, Porto Velho, RO, 2011. Disponível em: < http://ditel.casacivil.ro.gov.br/COTEL/Livros/detalhes.aspx?coddoc=3339>. Acesso em: 18 abr. 2020.

RONDÔNIA. Lei Estadual Complementar no 655 de 28 de março de 2012. Diário Oficial [do] Estado de Rondônia, Porto Velho, RO, 2012. Disponível em: < http://ditel.casacivil.ro.gov.br/COTEL/Livros/Files/LC655.pdf>. Acesso em: 06 set. 2020.

RONDÔNIA. Lei Estadual no 3.566, de 3 de junho de 2015. Diário Oficial [do] Estado de Rondônia, Porto Velho, RO. 2015. Disponível em: < http://ditel.casacivil.ro.gov.br/COTEL/Livros/detalhes.aspx?coddoc $=24825>$. Acesso em: 06 set. 2020.

SECRETARIA ESTADUAL DE AGRICULTURA (SEAGRI). Entrevista I. [jan. 2020]. Entrevistador: Eliane Alves da Silva. Porto Velho-RO, 2020. 1 arquivo.mp3 (30 min.).

SILVA, E. A.; PAES-DE-SOUZA, M; RODRÍGUEZ, T. D. M.; PEDROZO, E. A. Transição sociotécnica na cadeia produtiva do café no estado de Rondônia. Revista Ciências da Sociedade, v.4, n.7, p.144-163, 2020. Disponível em: < http://ufopa.edu.br/portaldeperiodicos/index.php/revistacienciasdasociedade/article/vie w/1404> Acesso em 06 abr. 2020.

SOUZA, V. A. Agroecologia, juventude e permanência no campo: uma relação possível?. Dissertação (Mestrado Profissional em Agroecossistemas). Universidade Federal de Santa Catarina. Centro de Ciências Agrárias. Programa de Pós-Graduação em Agroecossistemas - PAGR. Florianópolis, SC, 110 p., 2017. Disponível em: 
<https://repositorio.ufsc.br/bitstream/handle/123456789/186324/PAGR-P0058-

D.pdf?sequence=-1\&isAllowed=y> Acesso em: 29 mar. 2020.

TOLEDO, V. M. Indigenous peoples and biodiversity. In. LEVIN, S. A.

Encyclopedia of Biodiversity. PRINCETON: ACADEMIC Press, 2001, 4666p.

TRIVIÑOS, A. N. Introdução a pesquisa em ciências sociais: a pesquisa qualitativa em educação. São Paulo: Atlas, 2007.

Recebido em: 10/11/2021

Aprovado em: 02/12/2021

Publicado em: 08/12/2021 